\section{Kidney \\ Blood Pressure Research}

Kidney Blood Press Res 2018;43:406-421

DOI: $10.1159 / 000488121$

Published online: March 20, 2018

C) 2018 The Author(s)

Published by S. Karger AG, Basel

Accepted: March 9, 2018

www.karger.com/kbr

This article is licensed under the Creative Commons Attribution-NonCommercial-NoDerivatives 4.0 International License (CC BY-NC-ND) (http://www kargercom/Services/OpenAccessLicense). Usage and distribution for commercial purposes as well as any distribution of modified material requires written permission.

Review

\title{
Fabry Nephropathy: An Evidence-Based Narrative Review
}

\author{
María Dolores del Pino ${ }^{a} \quad$ Amado Andrés $^{b} \quad$ Ana Ávila Bernabéuc \\ Joaquín de Juan-Rivera ${ }^{d}$ Elvira Fernández ${ }^{e} \quad$ Juan de Dios García Díaz
} Domingo Hernández ${ }^{g}$ José Luño ${ }^{h}$ Isabel Martínez Fernández ${ }^{i} \quad$ José Paniaguaj Manuel Posada de la Paz ${ }^{k}$ José Carlos Rodríguez-Pérez Rafael Santamaríam Roser Torran $^{n}$ Joan Torras Ambros ${ }^{\circ}$ Pedro Vidau ${ }^{p} \quad$ Josep-Vicent Torregrosa ${ }^{q}$

aNephrology Service, Hospital Torrecardenas, Almeria, bivision of Nephrology, Instituto de Investigación Hospital 12 de Octubre, Universidad Complutense de Madrid, Madrid, cNephrology Department, Dr Peset University Hospital, Valencia, 'Nephrology Department, Elda General University Hospital. Elda, eUnit for the Detection and Treatment of Atherothrombotic Diseases (UDETMA), Nephrology Department, Hospital Universitari Arnau de Vilanova de Lleida, Institut de Recerca

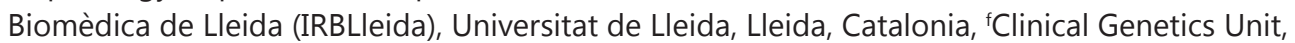
Department of Internal Medicine University Hospital Príncipe de Asturias Alcalá de Henares, Madrid, 9Nephrology Department, Carlos Haya Regional University Hospital and University of Málaga, IBIMA, REDinREN (RD16/0009/0006), Málaga, hNephrology Service, Hospital General Universitario Gregorio Marañón, Madrid, 'Nephrology Service, Hospital Galdakao-Usanzolo, Bizcaia, jNephrology Service, Hospital El Bierzo, Ponferrada (León), ' Institute of Rare Diseases Research, SpainRDR and CIBERER, Institute of Health Carlos III, Madrid, 'University Hospital of Gran Canaria Dr. Negrin, Universidad de Las Palmas de Gran Canaria (Las Palmas), mNephrology Department, Reina Sofia University Hospital, Maimonides Institute for Research in Biomedicine of Cordoba and University of Cordoba, Red de Investigación Renal (RedinRen), Cordoba, "Inherited Kidney Disorders, Nephrology Department, Fundació Puigvert, Instituto de Investigaciones Biomédicas Sant Pau (IIB-Sant Pau), Universitat Autònoma de Barcelona, REDinREN, Instituto de Investigación Carlos III, Barcelona, `Nephrology Service, Experimental Nephrology Laboratory, Hospital de Bellvitge, IDIBELL, Barcelona, Catalonia, pNephrology Service, Hospital Universitario Central de Asturias, Oviedo, aNephrology and Renal Transplant Department, Hospital Clinic, University of Barcelona, RedInRen, Barcelona, Spain

\section{Key Words}

Fabry disease $\bullet$ Nephropathy $•$ Proteinuria $\cdot$ Enzyme replacement therapy $\bullet$ Inherited disorder

\begin{abstract}
Fabry disease (FD) is a rare, X-linked disorder caused by mutations in the GLA gene encoding the enzyme $\alpha$-galactosidase A. Complete or partial deficiency in this enzyme leads to intracellular accumulation of globotriaosylceramide (Gb3) and other glycosphingolipids
\end{abstract}




\section{Kidney Blood Pressure Research}

in many cell types throughout the body, including the kidney. Progressive accumulation of Gb3 in podocytes, endothelial cells, epithelial cells, and tubular cells contribute to the renal symptoms of FD, which manifest as proteinuria and reduced glomerular filtration rate leading to renal insufficiency. A correct diagnosis of FD, although challenging, has considerable implications regarding treatment, management, and counseling. The diagnosis may be confirmed by demonstrating the enzyme deficiency in males and by identifying the specific GLA gene mutation in male and female patients. Treatment with enzyme replacement therapy, as part of the therapeutic strategy to prevent complications of the disease, may be beneficial in stabilizing renal function or slowing its decline, particularly in the early stages of the disease. Emergent treatments for FD include the recently approved chaperone molecule migalastat for patients with amenable mutations. The objective of this report is to provide an updated overview on Fabry nephropathy, with a focus on the most relevant aspects of its epidemiology, diagnosis, pathophysiology, and treatment options.

(C) 2018 The Author(s)

Published by S. Karger AG, Basel

\section{Introduction}

Fabry disease (FD), also called Anderson-Fabry disease, is an X-linked lysosomal storage disorder causing defects in the glycosphingolipid metabolic pathway due to deficient or absent lysosomal $\alpha$-galactosidase A ( $\alpha$-Gal A) activity. This results in the accumulation of globotriaosylceramide (Gb3) within lysosomes in a wide variety of cells, including endothelial, renal, cardiac, and dorsal root ganglion neuronal cells. The first descriptions of FD were made in 1898 by two physicians, William Anderson and Johannes Fabry, who described patients with 'angiokeratoma corporis diffusum' [1,2], the red-purple maculopapular skin lesions that represent a characteristic feature of the disease. The prevalence of FD is now estimated to be between 0.85 and 2.5 cases per 100, 000 individuals worldwide [3], although it may be largely underestimated due to the wide spectrum of clinical phenotypes. This spectrum ranges from the "classic" severe phenotype in males to an apparent asymptomatic disease course occasionally observed in females, with a variety of clinical presentations in between depending on the residual $\alpha$-Gal A activity, among other factors. The most common clinical features of FD include acroparesthesia and pain crisis, gastrointestinal disturbances, angiokeratomas and corneal dysfunction. If untreated, renal deposits, cardiomyopathy and/ or cerebrovascular disease lead to end-stage renal failure or cardiovascular events which may end in premature death, both in males and females $[4,5]$.

As FD is a progressive condition, a definitive diagnosis is crucial for patients having early access to optimal monitoring, supportive management, and appropriate treatment to prevent irreversible and life-threatening complications. In 2001, enzyme replacement therapy (ERT) for FD became available with the introduction of two products, agalsidase alfa (Replagal ${ }^{\circledR}$, Shire HGT Inc) and agalsidase beta (Fabrazyme ${ }^{\circledR}$, Genzyme Corp.). Agalsidase alfa and agalsidase beta are produced in different cell lines: agalsidase alfa is produced in a genetically engineered human cell line [6], whereas agalsidase beta is produced in a genetically modified CHO cell line [7]. Differences in the production process between agalsidase alfa and agalsidase beta lead to differences in their molecular structure [8-10]. Accordingly, agalsidase alfa and agalsidase beta have different optimal dosing regimens $[6,7]$. The introduction of ERT provided the first opportunity to address the underlying enzyme deficiency, allowing the removal of part of the Gb3 deposits, improvement of Fabryrelated symptoms and (potential) protection of severely affected organs [11-13]. However, a considerable number of FD patients develop disease manifestations despite treatment [14]. It has been shown that ERT may slow or prevent irreversible damage in the cardiac and renal systems if started at an earlier stage, but it has lower efficacy in advanced cases [15-17]. In this report we provide an overview on Fabry nephropathy, a prominent feature of FD, with a particular focus on the most relevant aspects of its epidemiology, diagnosis, pathophysiology, and treatment options. 


\section{Kidney Blood Pressure Research}

Kidney Blood Press Res 2018;43:406-421

\begin{tabular}{l|l}
\hline DOI: 10.1159/000488121 & (C) 2018 The Author(s). Published by S. Karger AG, Basel
\end{tabular}

Published online: March 20, 2018

www.karger.com/kbr

\section{Screening and prevalence of Fabry nephropathy}

FD screening among end-stage renal disease (ESRD) patients is an important clinical tool for the detection of FD patients, especially if it is followed by FD screening among family members of the index case, allowing genetic counseling and early therapeutic intervention [18]. Several studies have examined the prevalence of FD in high-risk populations such as patients with unexplained and overt left ventricular hypertrophy, premature strokes, or young ESRD patients [19]. A relevant study performed in Japan determined the frequency of unrecognized males with FD on chronic hemodialysis [20]. Six (1.2\%) of 514 screened patients had low plasma $\alpha$-Gal A activities and a missense mutation, and five of them presented as a novel "renal variant" phenotype, that was missing the classic symptoms of FD. Another Japanese study found one patient among $450(0.22 \%)$ dialysis patients with the renal variant of FD [21]. Tanaka et al. [22] identified four male patients with low leukocyte $\alpha$-Gal A and one female patient with low plasma $\alpha$-Gal A among 696 hemodialysis patients $(0.7 \%$ of the total population), highlighting that FD should be considered as the possible underlying etiology of unexplained ESRD not only in males but also in female patients undergoing hemodialysis.

In Austria, a cohort of 2480 patients ( $80.1 \%$ of the national dialysis population) was screened for the presence or absence of low $\alpha$-Gal A activity by means of a blood spot test. Further workup included measurement of enzyme activity in leukocytes, followed by mutation testing of the GLA gene in subjects with low enzyme activity. FD was confirmed in four patients, resulting in a prevalence of $0.161 \%$ among dialysis patients [23]. The same blood spot screening method was used for detection of unrecognized Fabry patients among chronic dialysis patients in the Czech Republic [24]. A total of 117 out of 3370 patients (3.5\%) tested positive (males 3.81\%, females 3.19\%). Based on consistently low $\alpha$-Gal A activity in plasma and leucocytes, and the results of molecular analysis, five patients (4/1521 males, $0.26 \% ; 1 / 1849$ females, $0.05 \%$ ) could be newly diagnosed with FD. The same approaches have resulted in prevalences of $0.36 \%$ in the Southern Brazilian State [25], 0.23\% in a Chinese population [26], 0.3-0.55\% in Spain [27, 28], 0.17\% in Turkey [29], and $0.02 \%$ in Japan [30].

Differences in the reported prevalence rates could be in part due to issues of laboratory methods and the choice of appropriate screening cutoff values. Most previous screening studies used a plasma $\alpha$-Gal A assay as the initial test, whereas some used blood spots. However, several limitations of the plasma/blood spot enzyme assays have been identified: occurrence of false-negative [31] and false-positive results [32]; false-negative results are not prevented by use of inhibitors of $\alpha$-galactosidase B activity [31]; and considerable intraindividual variability in plasma $\alpha$-galactosidase levels can reduce the discriminatory power of the screening test [31]. In addition, many females who are heterozygous for pathogenic GLA mutations have normal plasma $\alpha$-Gal A activity, and up to one third of female Fabry patients are not identified by enzyme activity analysis [33]. Also, the results of these screening studies haveve to be taken with caution as some of the so-called "missense mutations" found in some patients are in fact DNA variants with unknown clinical significance.

Serum Gb3 level determined by tandem mass spectrometry has also been evaluated as a biomarker for screening of FD among dialysis-dependent patients, but it is associated with a high rate of false-positives [34]. In urine samples, elevated Gb3 levels are present at birth in male FD patients, suggesting a very early involvement of the kidneys in the disease [35]. A transversal study investigated potential predictors of urinary Gb3 excretion in patients with chronic kidney disease (CKD), evaluating total Gb3, Gb3-24 isoform, and Gb3-24:18 isoform ratio by direct electrospray ionization mass spectrometry. The Gb3-24:18 isoform ratio was not affected by potential influencing variables and FD was the sole condition associated with elevated Gb3-24:18 isoform ratio, rendering it a potent screening tool in unselected cohorts of CKD [36]. 


\section{Kidney Blood Pressure Research}

With a different approach, Maruyama et al. [37] performed the first screening of dialysis patients for FD by measuring plasma Gb3 (lyso-Gb3), which has been shown to be clearly increased in the plasma of patients with symptomatic FD [38]. In this study, the plasma lyso-Gb3 screen identified FD with high sensitivity (100\%) and specificity (94.3\%), with a prevalence of FD in male dialysis patients of $0.07 \%$ [37].

In 2013, an Expert Consensus Document recommended to perform screening for FD in male CKD patients below 50 years of age in whom a reliable renal diagnosis is absent and in females with unexplained CKD, irrespective of age, with other unexplained symptoms potentially associated with FD. Recommendations for the screening methods were enzyme activity measurement for $\alpha$-Gal $A$ as a primary tool in males, followed by confirmation with mutation analysis when positive, and mutation analysis as a primary tool for screening in females [39]. However, in females with normal biochemical tests, it may be difficult to confirm or exclude the diagnosis of FD in the presence of a variant of unknown significance. Detection of the accumulating substance Gb3 in urine (rather than in plasma) could aid in detecting female heterozygotes and it can also be used in males as a surrogate marker to evaluate the response to ERT [40]. Plasma and urinary lyso-Gb3 may act as a biomarker/ diagnosing tool [41-43].

\section{Biomarkers and diagnostic studies for Fabry nephropathy}

As stated above, not all FD patients show the same clinical symptoms and, thus, diagnosis is often delayed, commonly for more than 15 years after the onset of the first manifestations [44]. Moreover, it has been reported that various drugs including amiodarone, chloroquine and hydroxychloroquine may mimic phospholipidosis of FD [45], so careful attention is required for the differential diagnosis of the disease. When classic skin and neurological features are absent, history of familial renal failure together with proteinuria may be suggestive of FD, and some specific mutations in the GLA gene, such as E66K, have been associated with preferential kidney involvement [46]. Of paramount importance is the detection of FD by family screening, as some relatives of an index case could be diagnosed at a younger age, before developing irreversible complications, and would benefit the most from the earlyinitiation of therapy [47]. It has been reported that for each index case, five additional immediate and extended family members, on average, can be diagnosed [48].

Several diagnostic approaches have been made, using different biomarkers and methods:

1) Microalbuminuria/proteinuria. In routine clinical practice, proteinuria and microalbuminuria are considered the earliest signs of FD nephropathy [49], although many new markers, including Gb3 [50], cystatin C [51, 52] and bikunin [53], have been suggested to improve the estimation of renal function impairment.

2) Podocyturia. A recent case report indicated that podocyturia precedes the appearance of proteinuria, and could be considered an even earlier biomarker of kidney damage [54]. Tondel et al. [55] studied young Fabry patients with normal albuminuria and glomerular filtration rate (GFR) that underwent renal biopsies to characterize the degree of renal tissue damage prior to initiation of ERT. Significant Gb3 accumulation was found in several types of kidney cells with high amounts of Gb3 in the podocytes, without signs of clinical kidney disease. An important finding was the detection of early segmental podocyte foot process effacement in most normoalbuminuric young classic Fabry patients, highlighting the relevance of kidney biopsies for the early diagnosis of nephropathy.

3) Urine microscopy has demonstrated usefulness in diagnosing FD, as vacuolated epithelial cells, filled with glycosphingolipids, giving the appearance of a 'Maltese cross', can be seen using polarized light microscopy [56]. One report has suggested that screening for mulberry cells (regarded as distal tubular epithelial cells in which Gb3 has accumulated) during urinalysis could be a simple, inexpensive, and non-invasive method for diagnosing this Fabry nephropathy in the absence of proteinuria [57]. 


\section{Kidney Blood Pressure Research}

4) Renal biopsy. A panel of nephrologists and international experts on FD indicated that a biopsy of the kidney with electron microscopy assessment is currently the only available tool that can reliably confirm or exclude FD nephropathy and should be considered in all patients without a classical pattern of disease manifestations, a GLA variant and CKD who have an uncertain diagnosis of FD [58]. This technique is also feasible for the routine study of paraffin-embedded kidney biopsies that have been immunostained with an anti-Gb3 antibody [59]. Of note, given that both the histological lesions (i.e. focal segmental glomerulosclerosis) and the clinical presentation (progressive proteinuria) are similar to that found in patients with either primary or secondary focal and segmental glomerulosclerosis (FSGS), an electron microscopy assessment should be performed in patients with unexplained FSGS [60]. A confirmatory study of $\alpha$-Gal A activity should also be done to rule out Fabry nephropathy.

5) Proteomic analysis. An approach using urine proteomic analysis based on capillary electrophoresis coupled to mass spectrometry identified a distinct peptide profile in the urine that characterized adult female Fabry patients. The pattern was able to distinguish female Fabry patients from healthy controls and from patients with various other forms of kidney or systemic diseases [61]. In this regard, it is considered that urinary Gb3 levels in the high range, as usually seen in classical males, can differentiate between classical FD and other diseases. Moreover, the deacylated form of Gb3, lyso-Gb3, can clearly differentiate classical from non-classical FD patients [38, 62]. However, Schiffmann et al. [63] showed a lack of correlation between changes from baseline at month 12 in urine and plasma Gb3 concentrations and renal outcomes, suggesting that changes in their levels do not predict clinical progression in FD.

\section{Mechanisms of Fabry nephropathy: natural course and complications}

Fabry nephropathy presents with a wide range of disease severity, both in males and females [64]; its overall rate of progression of CKD resembles that of diabetic nephropathy, and untreated patients frequently develop ESRD in their 50s [65], or even earlier [66]. Patients with Fabry nephropathy who develop kidney failure frequently suffer concurrent symptoms from other major organ systems [66].

Proteinuria is usually a manifestation of podocyte injury and urinary protein excretion is strongly associated with renal disease progression. Using data from 462 untreated adults (121 men and 341 women) who had at least two estimated GFR values over $>12$ months, Wanner et al. [67] found that patients with rapid progression had significantly higher mean averaged urinary protein to urinary creatinine ratios than patients with slower progression ( 1.5 vs 0.2 for men; 1.4 vs 0.5 for women; $\mathrm{p}<0.0001$ ). Other conditions, including hypertension, smoking, and hyperlipidemia, may also contribute to progressive loss of GFR in Fabry patients, as observed in other nephropathies [68]. Hypertension is not a common early finding in Fabry patients but becomes more prevalent with progression of the disease, and a significant percentage of patients have blood pressure above the recommended values for patients with CKD [64].

Kidney biopsy provided important information that was not available from routine assessment of kidney function and proteinuria, highlighting the role of kidney biopsy in the baseline evaluation of all Fabry patients, even with mild clinical disease. Histologically, renal involvement results from glycolipid deposits in glomerular cells (particularly in podocytes and also in mesangial cells and endothelial cells), tubular epithelial cells (particularly of the distal nephron), and arterial and arteriolar endothelial, smooth muscle cells, and interstitial cells, which is associated with an early concentrating defect [69]. These features can be present in children at very early stages of the disease [70,71]. Progression of kidney disease is characterized by proteinuria and irreversible ischemic changes in renal microvasculature that result in progressive glomerulosclerosis, capillary wall thickening, tubular atrophy, interstitial fibrosis, and arterial and arteriolar sclerosis. In one study, glomerulosclerosis 


\section{Kidney Blood Pressure Research}

and tubulointerstitial fibrosis were predictors of proteinuria and CKD stage in female patients [72], whereas another study found sclerosing/fibrotic changes in renal biopsies of Fabry patients involving glomeruli (25\% of the cases), interstitium (35\% of the cases) and vessels (50 to 60\%), with a negative correlation with renal function [73]. There has been an attempt to develop a standardized scoring system of both disease-specific lesions, i.e. lipid deposition related, and general lesions of progression, i.e. fibrosis and sclerosis, with the goal to determine whether baseline histologic information could be related to the rate of progression and/or response to ERT in Fabry nephropathy. The study showed that clinical disease was milder in the female cohort, with a corresponding lesser degree of global sclerosis and less podocyte, peritubular, vascular, and proximal tubule inclusions than in the males [74].

Some reports have documented the development of foot process effacement from podocyte injury in the absence of abnormalities in the urinalysis [75]. Podocytes are highly differentiated cells with a limited capacity for cell division and replacement, and podocyte injury and loss from the glomerulus results in ESRD by glomerular sclerosis [76]. There is evidence of progressive accumulation of podocyte Gb3 inclusions with increasing age in young Fabry patients with normal GFR and absent or low-grade proteinuria, with greater increases in foot process effacement in young male compared with female Fabry patients and normal subjects [77]. In cultured podocytes, lyso-Gb3, at concentrations found in the serum of Fabry patients, induced the production of mediators of podocyte injury, such as Notch1 signaling, which represents a molecular pathway of potential pathogenic significance in Fabry nephropathy $[78,79]$. Maurer et al. [80] showed a quantitative relationship in female Fabry patients between the X-inactivation phenomenon and podocyte injury manifesting as increased foot process effacement.

The assessment of renal function that should be carried out includes serum creatinine, cystatin C, estimates of GFR, total urinary protein excretion, (micro)albumin excretion, and urinary sodium excretion. The utility of urine protein/creatinine ratios and estimated GFR with the modification of diet with renal disease equation has been established [81]. Assessment of proteinuria and GFR can be used for the staging of CKD, as described in the Kidney Disease Outcomes Quality Initiative guidelines [82].

\section{Treatment of Fabry nephropathy}

Traditionally, treatment recommendations for Fabry nephropathy included controlling proteinuria to $<0.5 \mathrm{~g} /$ day, controlling blood pressure and hyperlipidemia, and initiating ERT at the first sign of kidney involvement (or at the time of diagnosis for patients with little or no residual $\alpha$-gal A activity) [83]. Those patients that develop kidney failure should undergo renal replacement therapy (dialysis or kidney transplantation).

The recommended therapeutic strategy for patients receiving ERT is to also receive angiotensin converting enzyme inhibitors (ACEIs) or angiotensin receptor blockers (ARBs) to reduce proteinuria [84]. The systematic use of antiproteinuric therapy with ACEIs and/ or ARBs was undertaken in a long-term open-label study of 10 patients [85]. They would historically have been at high risk for progressive loss of kidney function according to the phase III and phase IV results: baseline eGFR $<60 \mathrm{~mL} / \mathrm{min} / 1.73 \mathrm{~m}^{2}$, and baseline urine protein excretion $>1 \mathrm{~g} /$ day. When urine protein excretion was controlled to a target of $\leq 0.5$ g/day by carefully titrating ACEI and ARB doses in these adult Fabry patients who were also treated with agalsidase beta at $1 \mathrm{mg} / \mathrm{kg}$ every other week (EOW), the rate of loss of eGFR was not significantly different than zero [85]. A few years later, Warnock et al. [86] conducted a prospective observational study that examined the safety and efficacy of controlling proteinuria with ACEI or ARB therapy in FD patients who were receiving ERT with agalsidase beta. Results showed that proteinuria in most classical FD patients was controlled, but that kidney function was not preserved in patients who did not achieve the 


\section{Kidney Blood Pressure Research}

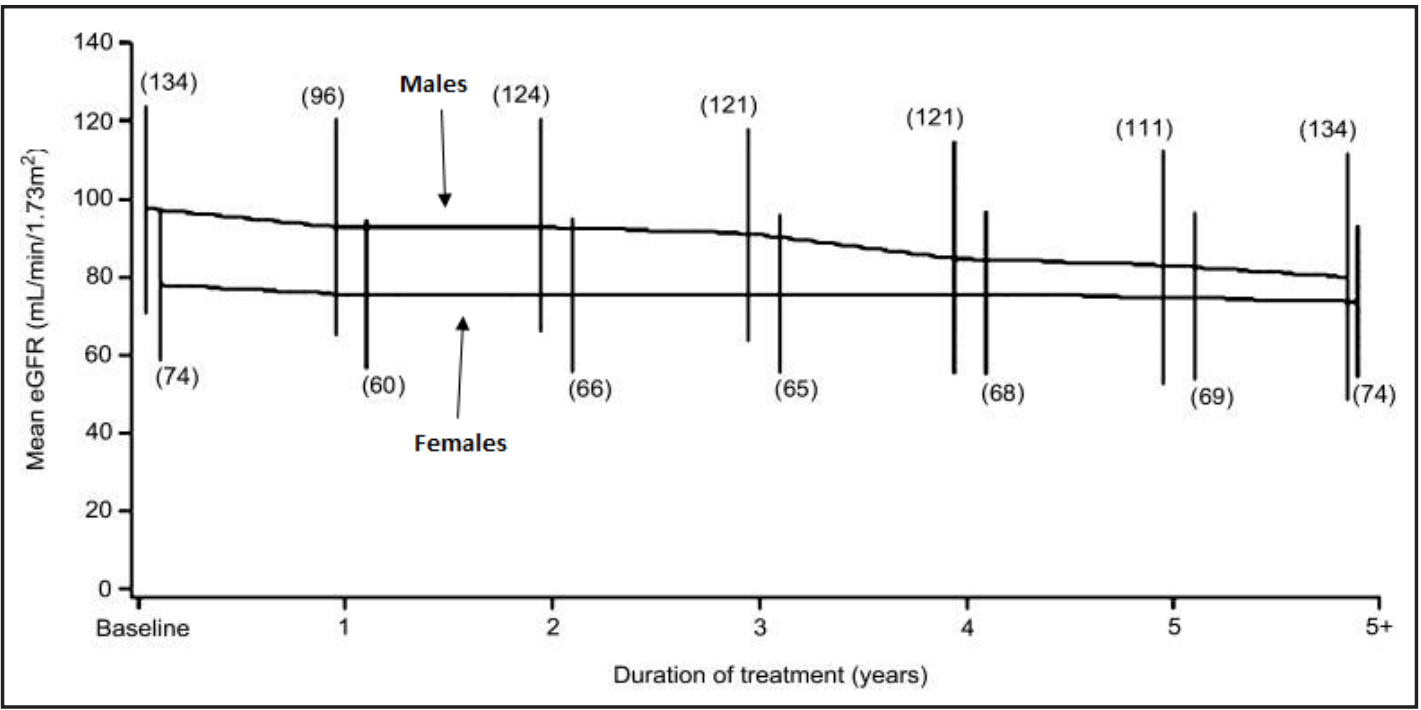

Fig. 1. Estimated GFR (eGFR) from baseline and throughout the follow-up in Fabry patients treated with agalsidase alfa. In parentheses: Numbers of patients in each group. Adapted from Feriozzi et al. (2012).

urine protein to creatinine ratio (UPCR) treatment goal of $0.5 \mathrm{~g} / \mathrm{g}$. Kidney function was preserved in a minority of patients who started ERT at a younger age, and who maintained a UPCR $<0.5 \mathrm{~g} / \mathrm{g}$ with antiproteinuric therapy [86]. There is some evidence supporting that the use of amiloride, a drug with proven effects in podocyte stabilization and proteinuria actions at the distal convoluted tubule, can decrease protein excretion in FD patients [87], but further research is needed. Another study evaluated the antiproteinuric effect of paricalcitol (PCT) in $15 \mathrm{FD}$ patients with proteinuria $>0.50 \mathrm{~g}$ /day persisting despite ERT and anti-renin-angiotensin system therapy titrated to maximum tolerated dosage [88]. Six months of add-on PCT significantly decreased proteinuria to $0.4 \pm 0.3 \mathrm{~g} /$ day, with levels $<0.50$ $\mathrm{g} /$ day achieved in four patients after 1 month, six after 3 months, and in 12 at 6 months, in the absence of changes to blood pressure and GFR. Interestingly, proteinuria recovered to basal values after PCT withdrawal [88].

As stated above, ERT could be provided by agalsidase alfa or agalsidase beta, by intravenous infusion at $0.2 \mathrm{mg} / \mathrm{kg}$ EOW and $1.0 \mathrm{mg} / \mathrm{kg}$ EOW, respectively. At this time, there is no robust evidence demonstrating superiority of either one in the treatment of FD [14, 89]. The first reports of ERT efficacy on renal outcomes were encouraging [11, 90]; reversal of renal glycosphingolipid accumulation in the vasculature and in other renal cell types and decrease of Gb3 in podocytes and distal tubular epithelium were observed after 11 months of agalsidase alfa treatment [91]. From the large international database Fabry Outcome Survey (FOS), several studies have confirmed that treatment with agalsidase alfa stabilizes or minimizes eGFR decline in both male and female Fabry patients [92-95]. The study by Feriozzi et al. [93], in 165 patients followed for 3 years on treatment, also showed how proteinuria influences the loss of eGFR, with an average of $1.68 \mathrm{~mL} / \mathrm{min} / 1.73 \mathrm{~m}^{2} /$ year in patients with baseline proteinuria $<0.50 \mathrm{~g} /$ day $(\mathrm{n}=40)$ and an average of $3.98 \mathrm{~mL} / \mathrm{min} / 1.73 \mathrm{~m}^{2} /$ year in patients with values $>0.50 \mathrm{~g} /$ day $(\mathrm{n}=14)$. These were confirmed by the same authors in a larger sample with a longer follow-up; in the whole cohort long-term ERT therapy was associated with a low decline in men and stabilization in women in the yearly reduction of eGFR (Fig. 1) [96]. In an analysis of pooled data from three randomized, placebo-controlled trials investigating the effect of ERT on renal function in a total of 108 adult male patients with FD, it was shown that measured GFR is stabilized for up to at least 4.5 years of treatment with agalsidase alfa [16]. A Brazilian study demonstrated that patients with mild (CKD stage 1) or moderate (CKD stage 3) renal impairment maintained stable GFRs over 3 years of treatment with agalsidase alfa. Only one patient (of 11), with stage 4 CKD, progressed to ESRD despite 


\section{Kidney Blood Pressure Research}

Kidney Blood Press Res 2018;43:406-421

\begin{tabular}{l|l}
\hline DOI: 10.1159/000488121 & (C) 2018 The Author(s). Published by S. Karger AG, Base
\end{tabular}

Published online: March 20, 2018

www.karger.com/kb

Del Pino et al.: Fabry Nepropathy

continuing agalsidase alfa infusions, without evidence of improvement in proteinuria with ERT until kidney transplantation [97]. At the histological level, a significant correlation has been shown between the reduction in podocyte Gb3 inclusions and the cumulative dose of agalsidase alfa or beta in young, predominantly male patients (one female patient) treated for a mean of 60.3 months; irrespective of drug dosage, complete clearance of Gb3 inclusions was observed in the glomerular endothelial cells and mesangial cells in all patients after 5 years of ERT [98]. Apart from the reported benefits of ERT on kidney function, several studies point to an action of this therapy against progression to cardiac and cerebrovascular complications $[12,94,95,99,100]$. In fact, risk of morbidity was reduced and survival was improved in treated patients from the FOS database compared to untreated groups from published literature [95]: median age at first composite event (renal, cardiac or stroke event, or death) was greater in agalsidase alfa-treated males and females, at 48 years and 56.9 years, respectively, compared with untreated patients, at 41 years and 53 years, respectively, whereas the estimated median survival time was 77.5 years for male patients from FOS compared with 60 years in patients without ERT.

Different dosing regimens of agalsidase alfa have been rarely investigated. Increasing the frequency of dosing with agalsidase alfa from EOW to weekly in a subgroup of patients with FD whose eGFR continued to decline at rapid rate while being treated EOW significantly slowed the rate of decline in eGFR. Nine of 11 patients (82\%) demonstrated either a positive eGFR slope $(n=3 ; 27 \%)$ or a slowing in their rate of decline (i.e., less negative eGFR slope; $\mathrm{n}=6 ; 55 \%$ ) after switching to weekly administration of agalsidase alfa. Only two patients had no improvement in their slope after switching from EOW to weekly dosing [101]. A randomized crossover study conducted by Hughes et al. [102] assessed the efficacy of three dosing schedules for FD $(0.2 \mathrm{mg} / \mathrm{kg}$ EOW, $0.1 \mathrm{mg} / \mathrm{kg}$ weekly and $0.2 \mathrm{mg} / \mathrm{kg}$ weekly, each for 4 weeks). Although the main analysis for pain and quality of life demonstrated no significant differences, there was a trend towards reduced urine Gb3 levels with weekly $0.2 \mathrm{mg} / \mathrm{kg}$ agalsidase alfa [102]. Comparing agalsidase alfa $0.2 \mathrm{mg} / \mathrm{kg}$ EOW with $0.2 \mathrm{mg} / \mathrm{kg}$ weekly over 1 year in treatment-naïve adults with FD, changes in eGFR were minimal and did not significantly differ between the two groups [103]. A global analysis by CKD stage showed that reductions in mean eGFR in patients with hyperfiltration (Stage $1 \mathrm{~A}, \geq 130 \mathrm{~mL} / \mathrm{min} / 1.73$ $\mathrm{m}^{2}$ ) occurred by week 13 and remained stable until the end of the study, indicating possible normalization of renal function in these patients. The eGFR of patients with all other CKD stages was maintained throughout, thus indicating that renal function remained stable with either dosing regimen. Urine albumina/creatinine ratio also showed no significant changes at the end of the study [103].

Even in patients with ESRD undergoing dialysis, ERT, by addressing the underlying metabolic deficiency, may slow the progression or development of extra-renal signs and symptoms of the disease and improve quality of life [104]. In a nationwide cross-sectional survey study with prospective follow-up, 33 Italian Fabry patients with ESRD that had either undergone kidney transplantation or were on maintenance dialysis therapy received ERT for a minimum of 3 years. Signs of progression of cardiomyopathy in Fabry patients on dialysis were observed, while Fabry patients with a renal allograft generally had a stable cardiac condition and a rate of decline in allograft renal function below levels reported for untreated non-ESRD Fabry patients [105]. Cybulla et al. [106] examined the effects of agalsidase alfa in 20 transplant patients with Fabry disease in terms of allograft function after a median of $\sim 3.5$ years of treatment. After 2 years of ERT, there was a non-significant increase in serum creatinine (1.4 mg/dL at baseline versus $1.6 \mathrm{mg} / \mathrm{dL}$ at 2 years) and a decrease in eGFR $(59.2$ $\mathrm{mL} / \mathrm{min} / 1.73 \mathrm{~m}^{2}$ at baseline versus $51.1 \mathrm{~mL} / \mathrm{min} / 1.73 \mathrm{~m}^{2}$ at 2 years), whereas proteinuria remained stable during this time period [106].

The results of the Phase IV agalsidase beta $(1 \mathrm{mg} / \mathrm{kg}$ ) clinical trial in patients with mild chronic renal failure demonstrated the beneficial effects of agalsidase beta, as it may slow the progression of renal insufficiency, particularly if therapy is started when eGFR is still above $55 \mathrm{~mL} / \mathrm{min}$ [12]. The Phase II agalsidase beta extension study showed that renal 


\section{Kidney Blood Pressure Research}

Kidney Blood Press Res 2018;43:406-421
\begin{tabular}{l|l} 
DOI: 10.1159/000488121 & $\begin{array}{l}\text { ( ) 2018 The Author(s). Published by S. Karger AG, Basel } \\
\text { www.karger.com/kbr }\end{array}$ \\
Published online: March 20, 2018 &
\end{tabular}

Del Pino et al.: Fabry Nepropathy

function in the majority of patients remained stable, which was accompanied by reduction of plasma Gb3 and clearance in glomerular, tubular and interstitial endothelial cells and different renal cell types. However, renal disease progressed in some patients, which seemed to be related to the severity of the disease before treatment (most had significant proteinuria and evidence of sclerotic glomeruli) [107]. Thus, the initiation of ERT before the development of significant proteinuria is considered essential to prevent future kidney disease in these patients, as supported by a retrospective analysis of the progression of renal disease in patients not receiving ERT [65]. ERT initiated prior to CKD stage 5 was shown to be associated with stability in cardiac and renal disease while patients with CKD stage 5 showed ongoing deterioration [108]. A 10-year observational study of 52 patients with classic FD investigated the effectiveness of agalsidase beta therapy $(1 \mathrm{mg} / \mathrm{kg}$ EOW) with regard to renal and other outcomes. Most patients remained alive and event-free, and mean plasma Gb3 normalized within 6 months. Mean slopes for eGFR were $-1.89 \mathrm{~mL} / \mathrm{min} / 1.73 \mathrm{~m}^{2}$ / year and $-6.82 \mathrm{~mL} / \mathrm{min} / 1.73 \mathrm{~m}^{2} /$ year for starting ERT with less and greater kidney damage, respectively [17]. In line with these results, Warnock et al. [109] confirmed that the patients treated with agalsidase beta with the most stable renal function had lower mean average UPCR levels and higher mean baseline eGFR levels than those with the fastest renal disease progression. By contrast, in women with FD and mild renal involvement ERT was associated with stable renal function and a reduction in albuminuria as well as the decreased excretion of both glomerular and tubular protein markers [110]. A recent analysis of data from adult patients with FD enrolled in the Fabry Registry determined trends in the incidence of severe, potentially life-threatening clinical events (renal failure, cardiac events, stroke, death) over time in patients receiving up to 5 years' treatment with agalsidase beta, at a dose of $1 \mathrm{mg} / \mathrm{kg}$ EOW [111]. The results showed that the incidence rate for severe clinical events decreased after the first 6 months of ERT; those patients at highest risk for severe clinical events, due to older age or male sex, displayed the greatest absolute reduction in event rate over time, and in particular had the greatest reduction in incidence rates for severe clinical events after the first 6 months of treatment [111]. Similarly, a single-center study of 57 ERT-treated patients observed that, in comparison to a historical group of untreated patients, the odds for development of a first severe clinical event declined with longer treatment duration per year of ERT (odds ratio $0.81,95 \%$ confidence interval 0.68 to 0.96 ) [100]. However, a cost-effectiveness study of ERT compared with standard medical care in a Dutch cohort of patients with FD concluded that in symptomatic patients, ERT has limited effect on quality of life and progression to end-organ damage, and this modest effectiveness drives the costs per quality of adjusted life years and the costs per year free of end-organ damage to millions of euros [112].

As part of the therapeutic strategies for FD, pharmacological chaperones have shown great promise for patients with specific mutations resulting in misfolded or unstable enzymes and, among them, migalastat has recently been approved for the treatment of FD [113]. Migalastat hydrochloride is an analog of the terminal galactose of $\mathrm{Gb} 3$ that binds and stabilizes wild type and mutant forms of $\alpha$-Gal A [114]. In a phase III trial of migalastat a significant and durable reduction in kidney Gb3 levels was seen in migalastat treated patients with amenable mutations [115]. Additionally, the annualized rates of change in eGFR among this group decreased less than the eGFR of historic untreated patients [65, 67], regardless of the baseline levels of urinary protein excretion. Other benefits of this agent include being non-invasive because it is taken orally, exhibiting broad tissue distribution [116], and gaining access to the central nervous system [117]. However, as a genotype-specific therapy it is estimated that only one-third of mutations may be amenable to migalastat. 


\section{Kidney Blood Pressure Research}

\section{Conclusion}

During the last decades, we have gained great knowledge about FD pathophysiology, natural course, and treatment, but many patients still receive the correct diagnosis rather late in the course of the disorder. Hence, it is essential to raise awareness of this disease in the general population and among physicians, as a definitive diagnosis in these cases has the potential to improve medical care in the affected individual, as well as perhaps leading to identification of the disease in relatives. All males who are hemizygous for FD can be diagnosed by demonstrating a deficiency of $\alpha$-Gal A activity in plasma and/or leukocytes, but the mutation in the GLA gene should be also determined. Heterozygous females cannot be diagnosed reliably by enzymatic assay because $\alpha$-Gal A activity in plasma varies according to inactivation of the $\mathrm{X}$ chromosome, so mutation analysis is the primary tool for screening in females.

Multiple studies have shown that the renal manifestations of FD occur early in life in a significant proportion of children, in many women, and in almost all men with this disorder. These manifestations progress to ESRD in nearly all males and some female patients. Proteinuria, as a manifestation of podocyte injury in Fabry nephropathy, is strongly associated with renal disease progression.

ERT with agalsidase alfa or agalsidase beta has become the major approach to the treatment of patients with FD. ERT slows or prevents irreversible damage in the cardiac and renal systems if started at an earlier stage, but it has lower efficacy in advanced stages. Adjunctive therapy from management of CKD and cardiovascular risk factors is also mandatory. Migalastat has recently been approved for the treatment of FD, with the advantages of its oral administration and broad tissue distribution. The ultimate goal of ERT and other therapies should be the avoidance of severe complications. In general, prevention is likely to be more effective than attempting to reverse already damaged organs in FD patients.

\section{Disclosure Statement}

The authors declare no conflict of interest.

\section{Acknowledgements}

The authors would like to thank Anabel Herrero on behalf of Springer Healthcare Communications for providing medical writing/editing services, and Sheridan Henness, $\mathrm{PhD}$, of Springer Healthcare Communications, for English language editing. Medical writing/ editing services were funded by the Spanish Society of Nephrology (Sociedad Española de Nefrología, SEN).

\section{References}

1 Anderson W: A case of “angeiokeratoma”. Br J Dermatol 1898;10:113-117.

2 Fabry J: Ein Beitrag zur Kenntnis der Purpura haemorrhagica nodularis (Purpura papulosa haemorrhagica Hebrae). Arch Dermatol Syph 1898;43:187-200.

3 Mehta A, Ricci R, Widmer U, Dehout F, Garcia de Lorenzo A, Kampmann C, Linhart A, Sunder-Plassmann G, Ries M, Beck M: Fabry disease defined: baseline clinical manifestations of 366 patients in the Fabry Outcome Survey. Eur J Clin Invest 2004;34:236-242. 


\section{Kidney \\ Blood Pressure Research}

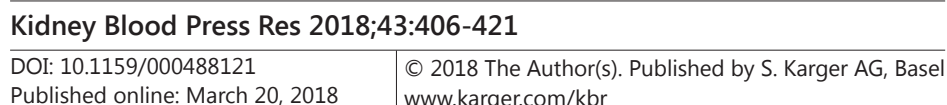

Published online: March 20, 2018 www.karger.com $/ \mathrm{kb}$

Del Pino et al.: Fabry Nepropathy

4 Waldek S, Patel MR, Banikazemi M, Lemay R, Lee P: Life expectancy and cause of death in males and females with Fabry disease: Findings from the Fabry Registry. Genet Med 2009;11:790-796.

5 Mehta A, Clarke JTR, Giugliani R, Elliott P, Linhart A, Beck M, Sunder-Plassmann G: Natural course of Fabry disease: changing pattern of causes of death in FOS - Fabry Outcome Survey. J Med Genet 2009;46:548552.

6 European Medicine Agency: Replagal $@$ SmPC 2015; http://www.ema.europa.eu/docs/en_GB/document_ library/EPAR_-_Summary_for_the_public/human/000369/WC500053606.pdf. Accessed on 23/01/2017.

7 European Medicine Agency: Fabrazyme® SmPC 2013; http://www.ema.europa.eu/docs/en_GB/ document_library/EPAR_-_Summary_for_the_public/human/000370/WC500020541.pdf. Accessed on 23/01/2017.

-8 Lee K, Jin X, Zhang K, Copertino L, Andrews L, Baker-Malcolm J, Geagan L, Qiu H, Seiger K, Barngrover D, McPherson JM, Edmunds T: A biochemical and pharmacological comparison of enzyme replacement therapies for the glycolipid storage disorder Fabry disease. Glycobiology 2003;13:305-313.

-9 Garman SC, Garboczi DN: The molecular defect leading to Fabry disease: structure of human alphagalactosidase. J Mol Biol 2004;337:319-335.

10 Bekri S: Importance of glycosylation in enzyme replacement therapy; in Mehta A, Beck M, and SunderPlassmann G (eds): Fabry Disease: Perspectives from 5 Years of FOS. Oxford: Oxford PharmaGenesis Ltd, 2006, Chapter 5.

11 Eng CM, Guffon N, Wilcox WR, Germain DP, Lee P, Waldek S, Caplan L, Linthorst GE, Desnick RJ: Safety and efficacy of recombinant human alpha-galactosidase A--replacement therapy in Fabry's disease. N Engl J Med 2001;345:9-16.

12 Banikazemi M, Bultas J, Waldek S, Wilcox WR, Whitley CB, McDonald M, Finkel R, Packman S, Bichet DG, Warnock DG, Desnick RJ: Agalsidase-beta therapy for advanced Fabry disease: a randomized trial. Ann Intern Med 2007;146:77-86.

13 Alegra T, Vairo F, de Souza MV, Krug BC, Schwartz IV: Enzyme replacement therapy for Fabry disease: A systematic review and meta-analysis. Genet Mol Biol 2012;35:947-954.

$\checkmark 14$ Vedder AC, Linthorst GE, Houge G, Groener JEM, Ormel EE, Bouma BJ, Aerts JMFG, Hirth A, Hollak CEM: Treatment of Fabry Disease: Outcome of a Comparative Trial with Agalsidase Alfa or Beta at a Dose of 0.2 mg/kg. PLoS One 2007;2:e598.

-15 Weidemann F, Niemann M, Breunig F, Herrmann S, Beer M, Stork S, Voelker W, Ertl G, Wanner C, Strotmann J: Long-term effects of enzyme replacement therapy on fabry cardiomyopathy: evidence for a better outcome with early treatment. Circulation 2009;119:524-529.

16 West M, Nicholls K, Mehta A, Clarke JT, Steiner R, Beck M, Barshop BA, Rhead W, Mensah R, Ries M, Schiffmann R: Agalsidase alfa and kidney dysfunction in Fabry disease. J Am Soc Nephrol 2009;20:11321139.

17 Germain DP, Charrow J, Desnick RJ, Guffon N, Kempf J, Lachmann RH, Lemay R, Linthorst GE, Packman S, Scott CR, Waldek S, Warnock DG, Weinreb NJ, Wilcox WR: Ten-year outcome of enzyme replacement therapy with agalsidase beta in patients with Fabry disease. J Med Genet 2015;52:353-358.

18 Bekri S, Enica A, Ghafari T, Plaza G, Champenois I, Choukroun G, Unwin R, Jaeger P: Fabry disease in patients with end-stage renal failure: the potential benefits of screening. Nephron Clin Pract 2005;101:c3338.

19 Linthorst GE, Bouwman MG, Wijburg FA, Aerts JM, Poorthuis BJ, Hollak CE: Screening for Fabry disease in high-risk populations: a systematic review. J Med Genet 2010;47:217-222.

20 Nakao S, Kodama C, Takenaka T, Tanaka A, Yasumoto Y, Yoshida A, Kanzaki T, Enriquez AL, Eng CM, Tanaka H, Tei C, Desnick RJ: Fabry disease: detection of undiagnosed hemodialysis patients and identification of a "renal variant" phenotype. Kidney Int 2003;64:801-807.

21 Ichinose M, Nakayama M, Ohashi T, Utsunomiya Y, Kobayashi M, Eto Y: Significance of screening for Fabry disease among male dialysis patients. Clin Exp Nephrol 2005;9:228-232.

22 Tanaka M, Ohashi T, Kobayashi M, Eto Y, Miyamura N, Nishida K, Araki E, Itoh K, Matsushita K, Hara M, Kuwahara K, Nakano T, Yasumoto N, Nonoguchi H, Tomita K: Identification of Fabry's disease by the screening of alpha-galactosidase A activity in male and female hemodialysis patients. Clin Nephrol 2005;64:281-287. 


\section{Kidney \\ Blood Pressure Research}

-23 Kotanko P, Kramar R, Devrnja D, Paschke E, Voigtlander T, Auinger M, Pagliardini S, Spada M, Demmelbauer K, Lorenz M, Hauser AC, Kofler HJ, Lhotta K, Neyer U, Pronai W, Wallner M, Wieser C, Wiesholzer M, Zodl H, Fodinger M, et al.: Results of a nationwide screening for Anderson-Fabry disease among dialysis patients. J Am Soc Nephrol 2004;15:1323-1329.

-24 Merta M, Reiterova J, Ledvinova J, Poupetova H, Dobrovolny R, Rysava R, Maixnerova D, Bultas J, Motan J, Slivkova J, Sobotova D, Smrzova J, Tesar V: A nationwide blood spot screening study for Fabry disease in the Czech Republic haemodialysis patient population. Nephrol Dial Transplant 2007;22:179-186.

25 Porsch DB, Nunes AC, Milani V, Rossato LB, Mattos CB, Tsao M, Netto C, Burin M, Pereira F, Matte U, Giugliani R, Barros EJ: Fabry disease in hemodialysis patients in southern Brazil: prevalence study and clinical report. Ren Fail 2008;30:825-830.

-26 Lv YL, Wang WM, Pan XX, Wang ZH, Chen N, Ye ZY, Xu J: A successful screening for Fabry disease in a Chinese dialysis patient population. Clin Genet 2009;76:219-221.

-27 Gaspar P, Herrera J, Rodrigues D, Cerezo S, Delgado R, Andrade CF, Forascepi R, Macias J, del Pino MD, Prados MD, de Alegria PR, Torres G, Vidau P, Sá-Miranda MC: Frequency of Fabry disease in male and female haemodialysis patients in Spain. BMC Med Genet 2010;11:1-7.

28 Herrera J, Miranda CS: Prevalence of Fabry's disease within hemodialysis patients in Spain. Clin Nephrol 2014;81:112-120.

29 Okur I, Ezgu F, Biberoglu G, Tumer L, Erten Y, Isitman M, Eminoglu FT, Hasanoglu A: Screening for Fabry disease in patients undergoing dialysis for chronic renal failure in Turkey: identification of new case with novel mutation. Gene 2013;527:42-47.

-30 Saito O, Kusano E, Akimoto T, Asano Y, Kitagawa T, Suzuki K, Ishige N, Akiba T, Saito A, Ishimura E, Hattori M, Hishida A, Guili C, Maruyama H, Kobayashi M, Ohashi T, Matsuda I, Eto Y: Prevalence of Fabry disease in dialysis patients: Japan Fabry disease screening study (J-FAST). Clin Exp Nephrol 2016;20:284-293.

-31 Andrade J, Waters PJ, Singh RS, Levin A, Toh BC, Vallance HD, Sirrs S: Screening for Fabry disease in patients with chronic kidney disease: limitations of plasma alpha-galactosidase assay as a screening test. Clin J Am Soc Nephrol 2008;3:139-145.

-32 Wallin EF, Clatworthy MR, Pritchard NR: Fabry disease: results of the first UK hemodialysis screening study. Clin Nephrol 2011;75:506-510.

-33 Linthorst GE, Vedder AC, Aerts JM, Hollak CE: Screening for Fabry disease using whole blood spots fails to identify one-third of female carriers. Clin Chim Acta 2005;353:201-203.

-34 Kim JY, Hyun YY, Lee JE, Yoon HR, Kim GH, Yoo HW, Cho ST, Chun NW, Jeoung BC, Kim HJ, Kim KW, Kim SN, Kim YA, Lee HA, Lee JY, Lee YC, Lim HK, Oh KS, Son SH, Yu BH, et al.: Serum globotriaosylceramide assay as a screening test for fabry disease in patients with ESRD on maintenance dialysis in Korea. Korean J Intern Med 2010;25:415-421.

35 Chien YH, Olivova P, Zhang XK, Chiang SC, Lee NC, Keutzer J, Hwu WL: Elevation of urinary globotriaosylceramide (GL3) in infants with Fabry disease. Mol Genet Metab 2011;102:57-60.

-36 Gaggl M, Hofer M, Weidner S, Kleinert J, Fauler G, Wallner M, Kotanko P, Paschke E, Sunder-Plassmann G: Interfering parameters in the determination of urinary globotriaosylceramide (Gb3) in patients with chronic kidney disease. J Nephrol 2015;28:679-689.

-37 Maruyama H, Takata T, Tsubata Y, Tazawa R, Goto K, Tohyama J, Narita I, Yoshioka H, Ishii S: Screening of male dialysis patients for Fabry Disease by plasma globotriaosylsphingosine. Clin J Am Soc Nephrol 2013;8:629-636.

-38 Rombach SM, Dekker N, Bouwman MG, Linthorst GE, Zwinderman AH, Wijburg FA, Kuiper S, Vd Bergh Weerman MA, Groener JE, Poorthuis BJ, Hollak CE, Aerts JM: Plasma globotriaosylsphingosine: diagnostic value and relation to clinical manifestations of Fabry disease. Biochim Biophys Acta 2010;1802:741-748.

-39 Terryn W, Cochat P, Froissart R, Ortiz A, Pirson Y, Poppe B, Serra A, Van Biesen W, Vanholder R, Wanner C: Fabry nephropathy: indications for screening and guidance for diagnosis and treatment by the European Renal Best Practice. Nephrol Dial Transplant 2013;28:505-517.

40 Gal A, Hughes DA, Winchester B: Toward a consensus in the laboratory diagnostics of Fabry disease recommendations of a European expert group. J Inherit Metab Dis 2011;34:509-514.

-41 Togawa T, Kodama T, Suzuki T, Sugawara K, Tsukimura T, Ohashi T, Ishige N, Suzuki K, Kitagawa T, Sakuraba H: Plasma globotriaosylsphingosine as a biomarker of Fabry disease. Mol Genet Metab 2010;100:257-261. 


\section{Kidney \\ Blood Pressure Research}

Del Pino et al.: Fabry Nepropathy

42 Paschke E, Fauler G, Winkler H, Schlagenhauf A, Plecko B, Erwa W, Breunig F, Urban W, Vujkovac B, SunderPlassmann G, Kotanko P: Urinary total globotriaosylceramide and isoforms to identify women with Fabry disease: a diagnostic test study. Am J Kidney Dis 2011;57:673-681.

43 Auray-Blais C, Blais CM, Ramaswami U, Boutin M, Germain DP, Dyack S, Bodamer O, Pintos-Morell G, Clarke JT, Bichet DG, Warnock DG, Echevarria L, West ML, Lavoie P: Urinary biomarker investigation in children with Fabry disease using tandem mass spectrometry. Clin Chim Acta 2015;438:195-204.

44 Eng CM, Fletcher J, Wilcox WR, Waldek S, Scott CR, Sillence DO, Breunig F, Charrow J, Germain DP, Nicholls K, Banikazemi M: Fabry disease: baseline medical characteristics of a cohort of 1765 males and females in the Fabry Registry. J Inherit Metab Dis 2007;30:184-192.

45 Bracamonte ER, Kowalewska J, Starr J, Gitomer J, Alpers CE: Iatrogenic phospholipidosis mimicking Fabry disease. Am J Kidney Dis 2006;48:844-850.

46 Cybulla M, Schaefer E, Wendt S, Ling H, Krober SM, Hovelborn U, Schandelmaier S, Rohrbach R, Neumann HP: Chronic renal failure and proteinuria in adulthood: Fabry disease predominantly affecting the kidneys. Am J Kidney Dis 2005;45:e82-89.

47 Rozenfeld PA, Ceci R, Roa N, Kisinovsky I: The Continuous Challenge of Diagnosing patients with Fabry disease in Argentina: Genotype, Experiences, Anecdotes, and New Learnings. JIENS 2015. DOI: $10.1177 / 2326409815613806$.

48 Laney DA, Fernhoff PM: Diagnosis of Fabry disease via analysis of family history. J Genet Couns 2008;17:7983.

49 Breunig F, Wanner C: Update on Fabry disease: kidney involvement, renal progression and enzyme replacement therapy. J Nephrol 2008;21:32-37.

50 Rozenfeld PA, De Francesco NP, Borrajo GJ, Ceci R, Fossati CA: An easy and sensitive method for determination of globotriaosylceramide (Gb3) from urinary sediment: utility for Fabry disease diagnosis and treatment monitoring. Clin Chim Acta 2009;403:194-197.

-51 Feriozzi S, Germain DP, Di Vito R, Legrand A, Ricci R, Barbey F: Cystatin C as a marker of early changes of renal function in Fabry nephropathy. J Nephrol 2007;20:437-443.

52 Torralba-Cabeza MA, Olivera S, Hughes DA, Pastores GM, Mateo RN, Perez-Calvo JI: Cystatin C and NTproBNP as prognostic biomarkers in Fabry disease. Mol Genet Metab 2011;104:301-307.

53 Lepedda AJ, Fancellu L, Zinellu E, De Muro P, Nieddu G, Deiana GA, Canu P, Concolino D, Sestito S, Formato M, Sechi G: Urine bikunin as a marker of renal impairment in Fabry's disease. Biomed Res Int 2013;2013:205948.

-54 Trimarchi H, Canzonieri R, Muryan A, Schiel A, Araoz A, Forrester M, Karl A, Lombi F, Andrews J, Pomeranz V, Rengel T, Zotta E: Copious Podocyturia without Proteinuria and with Normal Renal Function in a Young Adult with Fabry Disease. Case Rep Nephrol 2015;2015:257628.

55 Tondel C, Kanai T, Larsen KK, Ito S, Politei JM, Warnock DG, Svarstad E: Foot process effacement is an early marker of nephropathy in young classic Fabry patients without albuminuria. Nephron 2015;129:16-21.

-56 Selvarajah M, Nicholls K, Hewitson TD, Becker GJ: Targeted urine microscopy in Anderson-Fabry disease: a cheap, sensitive and specific diagnostic technique. Nephrol Dial Transplant 2011;26:3195-3202.

57 Nakamichi T, Miyazaki M, Nakayama K, Sato M, Akiu N, Sato T, Sato H, Ito S: Fabry's disease discovered with chance urinary mulberry cells: a case report. CEN Case Reports 2013;2:49-52.

-58 van der Tol L, Svarstad E, Ortiz A, Tondel C, Oliveira JP, Vogt L, Waldek S, Hughes DA, Lachmann RH, Terryn W, Hollak CE, Florquin S, van den Bergh Weerman MA, Wanner C, West ML, Biegstraaten M, Linthorst GE: Chronic kidney disease and an uncertain diagnosis of Fabry disease: approach to a correct diagnosis. Mol Genet Metab 2015;114:242-247.

59 Valbuena C, Leitao D, Carneiro F, Oliveira JP: Immunohistochemical diagnosis of Fabry nephropathy and localisation of globotriaosylceramide deposits in paraffin-embedded kidney tissue sections. Virchows Arch 2012;460:211-221.

60 Trimarchi H, Karl A, Rana MS, Forrester M, Pomeranz V, Lombi F, Lotti A: Initially Nondiagnosed Fabry's Disease when Electron Microscopy Is Lacking: The Continuing Story of Focal and Segmental Glomerulosclerosis. Case Rep Nephrol Urol 2013;3:51-57.

-61 Kistler AD, Siwy J, Breunig F, Jeevaratnam P, Scherl A, Mullen W, Warnock DG, Wanner C, Hughes DA, Mischak H, Wüthrich RP, Serra AL: A Distinct Urinary Biomarker Pattern Characteristic of Female Fabry Patients That Mirrors Response to Enzyme Replacement Therapy. PLoS One 2011;6:e20534. 


\section{Kidney \\ Blood Pressure Research}

-62 Niemann M, Rolfs A, Stork S, Bijnens B, Breunig F, Beer M, Ertl G, Wanner C, Weidemann F: Gene mutations versus clinically relevant phenotypes: lyso-Gb3 defines Fabry disease. Circ Cardiovasc Genet 2014;7:8-16.

63 Schiffmann R, Ries M, Blankenship D, Nicholls K, Mehta A, Clarke JT, Steiner RD, Beck M, Barshop BA, Rhead W, West M, Martin R, Amato D, Nair N, Huertas P: Changes in plasma and urine globotriaosylceramide levels do not predict Fabry disease progression over 1 year of agalsidase alfa. Genet Med 2013;15:983-989.

64 Ortiz A, Oliveira JP, Waldek S, Warnock DG, Cianciaruso B, Wanner C: Nephropathy in males and females with Fabry disease: cross-sectional description of patients before treatment with enzyme replacement therapy. Nephrol Dial Transplant 2008;23:1600-1607.

-65 Schiffmann R, Warnock DG, Banikazemi M, Bultas J, Linthorst GE, Packman S, Sorensen SA, Wilcox WR, Desnick RJ: Fabry disease: progression of nephropathy, and prevalence of cardiac and cerebrovascular events before enzyme replacement therapy. Nephrol Dial Transplant 2009;24:2102-2111.

66 Ortiz A, Cianciaruso B, Cizmarik M, Germain DP, Mignani R, Oliveira JP, Villalobos J, Vujkovac B, Waldek S, Wanner C, Warnock DG: End-stage renal disease in patients with Fabry disease: natural history data from the Fabry Registry. Nephrol Dial Transplant 2010;25:769-775.

67 Wanner C, Oliveira JP, Ortiz A, Mauer M, Germain DP, Linthorst GE, Serra AL, Marodi L, Mignani R, Cianciaruso B, Vujkovac B, Lemay R, Beitner-Johnson D, Waldek S, Warnock DG: Prognostic indicators of renal disease progression in adults with Fabry disease: natural history data from the Fabry Registry. Clin J Am Soc Nephrol 2010;5:2220-2228.

68 Remuzzi G, Benigni A, Remuzzi A: Mechanisms of progression and regression of renal lesions of chronic nephropathies and diabetes. J Clin Invest 2006;116:288-296.

69 Alroy J, Sabnis S, Kopp JB: Renal Pathology in Fabry Disease. J Am Soc Nephrol 2002;13:S134-S138.

-70 Najafian B, Mauer M, Hopkin RJ, Svarstad E: Renal complications of Fabry disease in children. Pediatr Nephrol 2013;28:679-687.

-71 Wijburg FA, Benichou B, Bichet DG, Clarke LA, Dostalova G, Fainboim A, Fellgiebel A, Forcelini C, An Haack K, Hopkin RJ, Mauer M, Najafian B, Scott CR, Shankar SP, Thurberg BL, Tondel C, Tylki-Szymanska A, Ramaswami U: Characterization of early disease status in treatment-naive male paediatric patients with Fabry disease enrolled in a randomized clinical trial. PLoS One 2015;10:e0124987.

72 Valbuena C, Carvalho E, Bustorff M, Ganhao M, Relvas S, Nogueira R, Carneiro F, Oliveira JP: Kidney biopsy findings in heterozygous Fabry disease females with early nephropathy. Virchows Arch 2008;453:329-338.

73 Noel LH, Laurent B, Grunfeld JP: [Renal biopsies in Fabry disease: a multicenter French study]. Nephrol Ther 2012;8:433-438.

74 Fogo AB, Bostad L, Svarstad E, Cook WJ, Moll S, Barbey F, Geldenhuys L, West M, Ferluga D, Vujkovac B, Howie AJ, Burns A, Reeve R, Waldek S, Noel LH, Grunfeld JP, Valbuena C, Oliveira JP, Muller J, Breunig F, et al.: Scoring system for renal pathology in Fabry disease: report of the International Study Group of Fabry Nephropathy (ISGFN). Nephrol Dial Transplant 2010;25:2168-2177.

-75 Kanai T, Yamagata T, Ito T, Odaka J, Saito T, Aoyagi J, Kobayashi M, Ohashi T, Ueda Y, Momoi MY: Foot process effacement with normal urinalysis in classic fabry disease. JIMD Rep 2011;1:39-42.

-76 Wiggins J: Podocytes and glomerular function with aging. Semin Nephrol 2009;29:587-593.

-77 Najafian B, Svarstad E, Bostad L, Gubler MC, Tondel C, Whitley C, Mauer M: Progressive podocyte injury and globotriaosylceramide (GL-3) accumulation in young patients with Fabry disease. Kidney Int 2011;79:663670.

78 Sanchez-Nino MD, Sanz AB, Carrasco S, Saleem MA, Mathieson PW, Valdivielso JM, Ruiz-Ortega M, Egido J, Ortiz A: Globotriaosylsphingosine actions on human glomerular podocytes: implications for Fabry nephropathy. Nephrol Dial Transplant 2011;26:1797-1802.

79 Sanchez-Nino MD, Carpio D, Sanz AB, Ruiz-Ortega M, Mezzano S, Ortiz A: Lyso-Gb3 activates Notch1 in human podocytes. Hum Mol Genet 2015;24:5720-5732.

80 Mauer M, Glynn E, Svarstad E, Tondel C, Gubler MC, West M, Sokolovskiy A, Whitley C, Najafian B: Mosaicism of podocyte involvement is related to podocyte injury in females with Fabry disease. PLoS One 2014;9:e112188.

-81 Rombach SM, Baas MC, ten Berge IJ, Krediet RT, Bemelman FJ, Hollak CE: The value of estimated GFR in comparison to measured GFR for the assessment of renal function in adult patients with Fabry disease. Nephrol Dial Transplant 2010;25:2549-2556. 


\section{Kidney \\ Blood Pressure Research}

Del Pino et al.: Fabry Nepropathy

82 Eng CM, Germain DP, Banikazemi M, Warnock DG, Wanner C, Hopkin RJ, Bultas J, Lee P, Sims K, Brodie SE, Pastores GM, Strotmann JM, Wilcox WR: Fabry disease: guidelines for the evaluation and management of multi-organ system involvement. Genet Med 2006;8:539-548.

83 Ortiz A, Oliveira JP, Wanner C, Brenner BM, Waldek S, Warnock DG: Recommendations and guidelines for the diagnosis and treatment of Fabry nephropathy in adults. Nat Clin Pract Nephrol 2008;4:327-336.

84 Pisani A, Visciano B, Imbriaco M, Di Nuzzi A, Mancini A, Marchetiello C, Riccio E: The kidney in Fabry's disease. Clin Genet 2014;86:301-309.

-85 Tahir H, Jackson LL, Warnock DG: Antiproteinuric therapy and fabry nephropathy: sustained reduction of proteinuria in patients receiving enzyme replacement therapy with agalsidase-beta. J Am Soc Nephrol 2007;18:2609-2617.

-86 Warnock DG, Thomas CP, Vujkovac B, Campbell RC, Charrow J, Laney DA, Jackson LL, Wilcox WR, Wanner C: Antiproteinuric therapy and Fabry nephropathy: factors associated with preserved kidney function during agalsidase-beta therapy. J Med Genet 2015;52:860-866.

87 Trimarchi H, Forrester M, Lombi F, Pomeranz V, Raña MS, Karl A, Andrews J: Amiloride as an Alternate Adjuvant Antiproteinuric Agent in Fabry Disease: The Potential Roles of Plasmin and uPAR. Case Rep Nephrol 2014;2014:6.

88 Pisani A, Sabbatini M, Duro G, Colomba P, Riccio E: Antiproteinuric effect of add-on paricalcitol in Fabry disease patients: a prospective observational study. Nephrol Dial Transplant 2015;30:661-666.

89 El Dib R, Gomaa H, Carvalho RP, Camargo SE, Bazan R, Barretti P, Barreto FC: Enzyme replacement therapy for Anderson-Fabry disease. Cochrane Database Syst Rev 2016;7:Cd006663.

-90 Schiffmann R, Kopp JB, Austin HA, 3rd, Sabnis S, Moore DF, Weibel T, Balow JE, Brady RO: Enzyme replacement therapy in Fabry disease: a randomized controlled trial. JAMA 2001;285:2743-2749.

-91 Thurberg BL, Rennke H, Colvin RB, Dikman S, Gordon RE, Collins AB, Desnick RJ, O’Callaghan M: Globotriaosylceramide accumulation in the Fabry kidney is cleared from multiple cell types after enzyme replacement therapy. Kidney Int 2002;62:1933-1946.

-92 Schwarting A, Dehout F, Feriozzi S, Beck M, Mehta A, Sunder-Plassmann G: Enzyme replacement therapy and renal function in 201 patients with Fabry disease. Clin Nephrol 2006;66:77-84.

-93 Feriozzi S, Schwarting A, Sunder-Plassmann G, West M, Cybulla M: Agalsidase alfa slows the decline in renal function in patients with Fabry disease. Am J Nephrol 2009;29:353-361.

94 Mehta A, Beck M, Elliott P, Giugliani R, Linhart A, Sunder-Plassmann G, Schiffmann R, Barbey F, Ries M, Clarke JT: Enzyme replacement therapy with agalsidase alfa in patients with Fabry's disease: an analysis of registry data. Lancet 2009;374:1986-1996.

-95 Beck M, Hughes D, Kampmann C, Larroque S, Mehta A, Pintos-Morell G, Ramaswami U, West M, Wijatyk A, Giugliani R: Long-term effectiveness of agalsidase alfa enzyme replacement in Fabry disease: A Fabry Outcome Survey analysis. Mol Genet Metab Rep 2015;3:21-27.

96 Feriozzi S, Torras J, Cybulla M, Nicholls K, Sunder-Plassmann G, West M: The effectiveness of long-term agalsidase alfa therapy in the treatment of Fabry nephropathy. Clin J Am Soc Nephrol 2012;7:60-69.

-97 Thofehrn S, Netto C, Cecchin C, Burin M, Matte U, Brustolin S, Nunes AC, Coelho J, Tsao M, Jardim L, Giugliani R, Barros EJ: Kidney function and 24-hour proteinuria in patients with Fabry disease during 36 months of agalsidase alfa enzyme replacement therapy: a Brazilian experience. Ren Fail 2009;31:773-778.

\$8 Tondel C, Bostad L, Larsen KK, Hirth A, Vikse BE, Houge G, Svarstad E: Agalsidase Benefits Renal Histology in Young Patients with Fabry Disease. J Am Soc Nephrol 2012;24:137-148.

$\$ 99$ Zamorano J, Serra V, Perez de Isla L, Feltes G, Calli A, Barbado FJ, Torras J, Hernandez S, Herrera J, Herrero JA, Pintos G: Usefulness of tissue Doppler on early detection of cardiac disease in Fabry patients and potential role of enzyme replacement therapy (ERT) for avoiding progression of disease. Eur J Echocardiogr 2011;12:671-677.

100 Rombach SM, Smid BE, Bouwman MG, Linthorst GE, Dijkgraaf MG, Hollak CE: Long term enzyme replacement therapy for Fabry disease: effectiveness on kidney, heart and brain. Orphanet J Rare Dis 2013;8:47.

101 Schiffmann R, Askari H, Timmons M, Robinson C, Benko W, Brady RO, Ries M: Weekly enzyme replacement therapy may slow decline of renal function in patients with Fabry disease who are on long-term biweekly dosing. J Am Soc Nephrol 2007;18:1576-1583. 


\section{Kidney \\ Blood Pressure Research}

102 Hughes DA, Deegan PB, Milligan A, Wright N, Butler LH, Jacobs A, Mehta AB: A randomised, double-blind, placebo-controlled, crossover study to assess the efficacy and safety of three dosing schedules of agalsidase alfa enzyme replacement therapy for Fabry disease. Mol Genet Metab 2013;109:269-275.

103 Goláň L, Goker-Alpan O, Holida M, Kantola I, Klopotowski M, Kuusisto J, Linhart A, Musial J, Nicholls K, Gonzalez-Rodriguez D, Sharma R, Vujkovac B, Chang P, Wijatyk A: Evaluation of the efficacy and safety of three dosing regimens of agalsidase alfa enzyme replacement therapy in adults with Fabry disease. Drug Des Devel Ther 2015;9:3435-3444.

104 Pisani A, Spinelli L, Sabbatini M, Andreucci MV, Procaccini D, Abbaterusso C, Pasquali S, Savoldi S, Comotti C, Cianciaruso B: Enzyme replacement therapy in Fabry disease patients undergoing dialysis: effects on quality of life and organ involvement. Am J Kidney Dis 2005;46:120-127.

105 Mignani R, Feriozzi S, Pisani A, Cioni A, Comotti C, Cossu M, Foschi A, Giudicissi A, Gotti E, Lozupone VA, Marchini F, Martinelli F, Bianco F, Panichi V, Procaccini DA, Ragazzoni E, Serra A, Soliani F, Spinelli L, Torti G, et al.: Agalsidase therapy in patients with Fabry disease on renal replacement therapy: a nationwide study in Italy. Nephrol Dial Transplant 2008;23:1628-1635.

106 Cybulla M, Walter KN, Schwarting A, Divito R, Feriozzi S, Sunder-Plassmann G: Kidney transplantation in patients with Fabry disease. Transpl Int 2009;22:475-481.

107 Germain DP, Waldek S, Banikazemi M, Bushinsky DA, Charrow J, Desnick RJ, Lee P, Loew T, Vedder AC, Abichandani R, Wilcox WR, Guffon N: Sustained, long-term renal stabilization after 54 months of agalsidase beta therapy in patients with Fabry disease. J Am Soc Nephrol 2007;18:1547-1557.

108 Talbot AS, Lewis NT, Nicholls KM: Cardiovascular outcomes in Fabry disease are linked to severity of chronic kidney disease. Heart 2015;101:287-293.

109 Warnock DG, Ortiz A, Mauer M, Linthorst GE, Oliveira JP, Serra AL, Marodi L, Mignani R, Vujkovac B, BeitnerJohnson D, Lemay R, Cole JA, Svarstad E, Waldek S, Germain DP, Wanner C: Renal outcomes of agalsidase beta treatment for Fabry disease: role of proteinuria and timing of treatment initiation. Nephrol Dial Transplant 2012;27:1042-1049.

110 Prabakaran T, Birn H, Bibby BM, Regeniter A, Sorensen SS, Feldt-Rasmussen U, Nielsen R, Christensen EI: Long-term enzyme replacement therapy is associated with reduced proteinuria and preserved proximal tubular function in women with Fabry disease. Nephrol Dial Transplant 2014;29:619-625.

111 Ortiz A, Abiose A, Bichet DG, Cabrera G, Charrow J, Germain DP, Hopkin RJ, Jovanovic A, Linhart A, Maruti SS, Mauer M, Oliveira JP, Patel MR, Politei J, Waldek S, Wanner C, Yoo H-W, Warnock DG: Time to treatment benefit for adult patients with Fabry disease receiving agalsidase $\beta$ : data from the Fabry Registry. J Med Genet 2016;53:495-502.

112 Rombach SM, Hollak CE, Linthorst GE, Dijkgraaf MG: Cost-effectiveness of enzyme replacement therapy for Fabry disease. Orphanet J Rare Dis 2013;8:1-9.

113 Gaggl M, Sunder-Plassmann G: Fabry disease: A pharmacological chaperone on the horizon. Nat Rev Nephrol 2016;12:653-654.

114 Johnson FK, Mudd PN, DiMino T, Vosk J, Sitaraman S, Boudes P, France N, Barlow C: An open-label study to determine the pharmacokinetics and safety of migalastat $\mathrm{HCl}$ in subjects with impaired renal function and healthy subjects with normal renal function. Clin Pharmacol Drug Devel 2015;4:256-261.

-115 Germain DP, Hughes DA, Nicholls K, Bichet DG, Giugliani R, Wilcox WR, Feliciani C, Shankar SP, Ezgu F, Amartino H, Bratkovic D, Feldt-Rasmussen U, Nedd K, Sharaf El Din U, Lourenco CM, Banikazemi M, Charrow J, Dasouki M, Finegold D, Giraldo P, et al.: Treatment of Fabry's Disease with the Pharmacologic Chaperone Migalastat. N Engl J Med 2016;375:545-555.

116 Johnson FK, Mudd PN, Jr., Bragat A, Adera M, Boudes P: Pharmacokinetics and Safety of Migalastat $\mathrm{HCl}$ and Effects on Agalsidase Activity in Healthy Volunteers. Clin Pharmacol Drug Dev 2013;2:120-132.

117 Benjamin ER, Flanagan JJ, Schilling A, Chang HH, Agarwal L, Katz E, Wu X, Pine C, Wustman B, Desnick RJ, Lockhart DJ, Valenzano KJ: The pharmacological chaperone 1-deoxygalactonojirimycin increases alphagalactosidase A levels in Fabry patient cell lines. J Inherit Metab Dis 2009;32:424-440. 